Physical activity correlates among 24,230 people with depression across 46 low- and middle-income countries

\title{
Vancampfort, Davy
}

2017-10-15

Vancampfort, D , Stubbs , B , Firth , J , Hallgren, M , Schuch , F , Lahti , J, Rosenbaum , S , Ward , P B , Mugisha , J , Carvalho , A F \& Koyanagi , A 2017 , ' Physical activity correlates among 24,230 people with depression across 46 low- and middle-income countries ' , Journal of Affective Disorders , vol. 221 , pp. 81-88 . https://doi.org/10.1016/j.jad.2017.06.012

http://hdl.handle.net/10138/297914

https://doi.org/10.1016/j.jad.2017.06.012

unspecified

publishedVersion

Downloaded from Helda, University of Helsinki institutional repository.

This is an electronic reprint of the original article.

This reprint may differ from the original in pagination and typographic detail.

Please cite the original version. 
Research paper

\title{
Physical activity correlates among 24,230 people with depression across 46 low- and middle-income countries
}

\author{
Davy Vancampfort ${ }^{\mathrm{a}, \mathrm{b}, *}$, Brendon Stubbs ${ }^{\mathrm{c}, \mathrm{d}}$, Joseph Firth $^{\mathrm{e}, \mathrm{r}}$, Mats Hallgren ${ }^{\mathrm{f}}$, Felipe Schuch ${ }^{\mathrm{g}, \mathrm{h}}$, \\ Jouni Lahti ${ }^{\mathrm{i}}$, Simon Rosenbaum ${ }^{\mathrm{j}, \mathrm{k}}$, Philip B. Ward ${ }^{\mathrm{k}, \mathrm{l}}$, James Mugisha ${ }^{\mathrm{m}, \mathrm{n}}$, André F. Carvalho ${ }^{\circ}$, \\ Ai Koyanagi ${ }^{\mathrm{p}, \mathrm{q}}$ \\ ${ }^{\text {a }}$ KU Leuven Department of Rehabilitation Sciences, Leuven, Belgium \\ b University Psychiatric Centre KU Leuven, Kortenberg, Belgium \\ c Physiotherapy Department, South London and Maudsley NHS Foundation Trust, Denmark Hill, London, United Kingdom \\ ${ }^{\mathrm{d}}$ Health Service and Population Research Department, Institute of Psychiatry, Psychology and Neuroscience, King's College London, De Crespigny Park, London, United \\ Kingdom \\ e Division of Psychology and Mental Health, University of Manchester, Manchester, United Kingdom \\ ${ }^{\mathrm{f}}$ Department of Public Health Sciences, Karolinksa Institute, Stockholm, Sweden \\ ${ }^{g}$ Unilasalle, Canoas, Brazil \\ ${ }^{\mathrm{h}}$ Hospital de Clínicas de Porto Alegre, Porto Alegre, Brazil \\ ${ }^{i}$ Department of Public Health, University of Helsinki, Helsinki, Finland \\ j Black Dog Institute, Randwick, Australia \\ ${ }^{k}$ School of Psychiatry, UNSW, Sydney, Australia \\ ${ }^{1}$ Schizophrenia Research Unit, Ingham Institute of Applied Medical Research, Liverpool, Australia \\ m Kyambogo University, Kampala, Uganda \\ n Butabika National Referral and Mental Health Hospital, Kampala, Uganda \\ - Department of Clinical Medicine and Translational Psychiatry Research Group, Faculty of Medicine, Federal University of Ceará, Fortaleza, Brazil \\ P Research and Development Unit, Parc Sanitari Sant Joan de Déu, Universitat de Barcelona, Fundació Sant Joan de Déu, Sant Boi de Llobregat, Barcelona, Spain \\ q Instituto de Salud Carlos III, Centro de Investigación Biomédica en Red de Salud Mental, CIBERSAM, Madrid, Spain \\ ${ }^{\mathrm{r}}$ NICM, School of Science and Health, University of Western Sydney, Australia
}

\section{A R T I C L E I N F O}

\section{Keywords:}

Physical activity

Exercise

Depression

\begin{abstract}
A B S T R A C T
Background: There is a paucity of nationally representative data available on the correlates of physical activity (PA) among people with depression, especially in low- and middle-income countries (LMICs). Thus, we investigated PA correlates among community-dwelling adults with depression in this setting.

Methods: World Health Survey data included 24,230 adults (43.1 \pm 16.1 years; $36.1 \%$ male) with ICD-10 diagnoses of depression including brief depressive episode and subsyndromal depression aged $\geq 18$ years from 46 LMICs. PA was assessed by the International Physical Activity Questionnaire. Participants were dichotomised into low and moderate-to-high physically active groups. Associations between PA and a range of sociodemographic, health behaviour and mental and physical health variables were examined using multivariable logistic regressions.

Results: $34.8 \%$ of participants with depression were physically inactive. In the multivariate analyses, inactivity was associated with male sex, older age, not being married/cohabiting, high socio-economic status, unemployment, living in an urban setting, less vegetable consumption, and poor sleep/ low energy. In addition, mobility difficulties and some somatic co-morbidity were associated with not complying with the $150 \mathrm{~min}$ per week moderate-to-vigorous PA recommendations.

Conclusions: The current data provide guidance for future population level interventions across LMICs to help people with depression engage in regular PA.
\end{abstract}

\footnotetext{
* Correspondence to: Tervuursevest 101, 3001 Leuven, Belgium.

E-mail address: davy.vancampfort@kuleuven.be (D. Vancampfort).
} 


\section{Introduction}

Depression is common, affects in excess of 350 million people worldwide and is the third leading cause of global disability according to the most recent Global Burden of Disease (2015) study (Vos et al., 2016). Depressive disorders affect people of all ages, both sexes, irrespective of socioeconomic status (Djernes, 2006; Kessler et al., 2003). Next to the tremendous mental health burden, people with depressive disorders are at elevated risk of various somatic co-morbidities. For example, depression is an independent risk factor for type 2 diabetes (Vancampfort et al., 2016, 2015b) and cardiovascular diseases (Seldenrijk et al., 2015). These cardio-metabolic diseases are also leading contributors to the increased premature mortality observed among people with depression (Correll et al., 2017; Walker et al., 2015).

In the general population, there is evidence that physical activity could be broadly as effective as pharmacological interventions in preventing and managing cardio-metabolic diseases and premature mortality (Naci and Ioannidis, 2013). Moreover, people who engage in low levels of physical activity (Mammen and Faulkner, 2013) and those with low cardiorespiratory fitness (Schuch et al., 2016b) appear to be at an increased risk of developing depression. There is also robust evidence demonstrating that physical activity is effective for the management of depression (Schuch et al., 2016a).

Despite the plethora of research pointing to beneficial effects associated with physical activity participation, many people with depression do not meet the recommended $150 \mathrm{~min} /$ week of moderate to vigorous physical activity (Schuch et al., 2017). For example, a recent multi-national study using data on 178,867 people from 36 low- and middle-income countries (LMICs) assessed physical activity levels with the International Physical Activity Questionnaire (Craig et al., 2003), and found that significantly more people with depression failed to comply with international physical activity recommendations compared with non-depressive individuals $(26.0 \%$ vs. $15.8 \%, \mathrm{P}<0.0001)$ (Stubbs et al., 2016b). Given the health benefits of physical activity, there is a need for research to investigate what factors influence physical activity participation in people with depression. A systematic review including 59 papers and involving 101,539 persons with depression (Vancampfort et al., 2015c) showed that the correlates consistently associated with lower physical activity participation were: a higher level of depressive symptoms, a higher body mass index, the presence of somatic co-morbidity and a lower self-efficacy. However, these findings were mainly based on studies from high-income countries while data from LMICs is scarce. This is an important research gap given the suboptimal treatment of depression (Patel et al., 2007), differences in knowledge regarding the benefits of physical activity (Pengpid et al., 2015), and different environmental factors such as different work conditions (Atkinson et al., 2016) in LMICs. The continuing dearth of studies from LMICs also highlights the gap between where research is conducted and where the largest public health impacts of physical inactivity occur (Sallis et al., 2016a). Information on physical activity correlates for people with depression in LMICs could guide the design and delivery of targeted interventions in these countries. It could also provide useful information that can support integration of physical activity into primary health care settings in many LMICs.

Thus, given the aforementioned gaps within the literature, we aimed to assess physical activity correlates among community-dwelling adults across the whole depressive spectrum in 46 LMICs.

\section{Methods}

\subsection{Settings and protocol}

The World Health Survey (WHS) was a cross-sectional study undertaken from 2002 to 2004 in 70 countries worldwide. Single-stage random sampling and stratified multi-stage random cluster sampling were conducted in 10 and 60 countries respectively. Individuals with depressive symptoms aged $\geq 18$ years with a valid home address were eligible to participate in this study. People were not excluded if they had a comorbid serious mental illness (e.g. schizophrenia). Each member of the household had equal probability of being selected with the use of Kish tables. The data were collected in all countries using the same questionnaires with some countries using a shorter version by face-to-face interviews. The individual response rate ranged from 63\% (Israel) to 99\% (Philippines) (Moussavi et al., 2007). Ethical approval was obtained from ethical boards at each study site. Sampling weights were generated to adjust for non-response and the population distribution reported by the United Nations Statistical Division. Informed consent was obtained from all participants. Details of the survey have been provided elsewhere (http://www.who.int/healthinfo/survey/en/). All interested researchers can gain access to the dataset through this website subject to approval from the World Health Organization.

\subsection{Variables}

\subsubsection{Depression}

Depressive symptoms were classified based on individual questions from the WHS version of the World Health Organization World Mental Health Composite International Diagnostic Interview which captures the duration and persistence of depressive symptoms in the preceding 12 months (Kessler and Ustun, 2004). We established three mutually exclusive groups based on the ICD-10 Diagnostic Criteria for Research (ICD-10-DCR) (World Health Organization, 1993) where criterion B referred to symptoms of depressed mood, loss of interest, and fatigability. In accordance with previous WHS publications (Ayuso-Mateos et al., 2010; Stubbs et al., 2016b), the algorithms used to define the three groups were the following: (a) Depressive episode group: at least two criterion B symptoms with a total of at least four depressive symptoms lasting two weeks most of the day or all of the day. (b) Brief depressive episode group: same criteria as depressive episode but did not meet the two-week duration criterion. (c) Subsyndromal depression: at least one criterion B symptom with the total number of symptoms being three or less, lasting two weeks most of the day or all of the day. The criteria of duration of at least two weeks and presence of symptoms during most of the day had to be met.

\subsubsection{Physical activity}

In order to assess if participants completed the recommended physical activity levels of $150 \mathrm{~min}$ of moderate to vigorous physical activity per week (Vancampfort et al., 2012a), we used data from the International Physical Activity Questionnaire (Craig et al., 2003). The total amount of moderate to vigorous physical activity over the last week was calculated based on self-reported (time spent physically active and frequency) moderate and high intensity physical activity. Those scoring $\geq 150$ min of moderate to high intensity physical activity were classified as meeting the recommended guidelines (coded 0), and those scoring $<150 \mathrm{~min}$ (low physical activity) were classified as not meeting the recommended guidelines (coded 1).

\subsubsection{Sociodemographic domain}

These included information on sex, age (18-24, 25-34, 35-44, $45-54,55-64$, $\geq 65$ years), marital status [Married/cohabiting or other (never married/separated/divorced/widowed)], highest education attained (at least secondary completed or not), wealth quintiles, employment status (unemployed or not), and setting (rural or urban). Principal component analysis based on 15-20 assets was performed to establish country-wise wealth quintiles. Employment status was assessed with the question 'What is your current job?'. Those who answered 'not working for pay' were considered to be unemployed.

\subsubsection{Health behaviour domain}

The question 'Do you currently smoke any tobacco products such as 
cigarettes, cigars, or pipes?' with the answer options being 'daily', 'yes, but not daily', or 'no, not at all' was used to identify current smokers. Those who replied 'daily' or 'yes, but not daily' were considered to be current smokers. Two separate questions for fruits and vegetables were used to assess the number of servings the participant eats on a typical day. The answer to these questions were dichotomized as $<5$ or $\geq 5$ servings/day following WHO/FAO recommendations (Bishwajit et al., 2017). Alcohol consumption was assessed by first asking the question 'Have you ever consumed a drink that contains alcohol (such as beer, wine, etc.)?' Respondents who replied 'no' were considered lifetime abstainers. If the respondent replied affirmatively, then he/she was asked how many standard drinks of any alcoholic beverage he/she had on each day of the past 7 days. The number of days in the past week in which 4 (female) or 5 (male) drinks were consumed was calculated (World Health Organization, 2002), and a total of 1-2 and $\geq 3$ days in the past 7 days were considered infrequent and frequent heavy drinking respectively. All other respondents, apart from lifetime abstainers, were considered non-heavy drinkers.

\subsubsection{Mental health domain}

Type of depression included depressive episode, brief depressive episode, and subsyndromal depression following the ICD-10 algorithm mentioned above. Anxiety was assessed by the question 'Overall in the past 30 days, how much of a problem did you have with worry or anxiety' with answer options being none, mild, moderate, severe, and extreme. In accordance with previous WHS publications, those who answered severe and extreme were considered to have anxiety (Koyanagi and Stickley, 2015; Wong et al., 2013). Details for the variables on sleep/energy and cognition are provided below (section on health status).

\subsubsection{Physical health domain}

Visual impairment was defined as having extreme difficulty in seeing and recognizing a person that the participant knows across the road (i.e., from a distance about $20 \mathrm{~m}$ ) (Freeman et al., 2013). A validity study showed that this response likely corresponds to World Health Organization definitions of visual impairment (Freeman et al., 2013). The participant was considered to have hearing problems if the interviewer observed this condition at the end of the survey. Arthritis, asthma, and diabetes were based on self-reported lifetime diagnosis. For angina, in addition to a self-reported diagnosis, a symptom-based diagnosis based on the Rose questionnaire was also used (Rose, 1962). Details on the variables on pain/discomfort and mobility are provided in the section below (section on health status).

\subsubsection{Health status (sleep/energy, cognition, pain/discomfort, mobility)}

Participants' health status was evaluated with 8 health-related questions pertaining to four domains: (a) sleep/energy; (b) cognition; (d) pain/discomfort; (g) mobility. These domains correspond to those commonly used in health related quality of life outcome measures such as the Short Form-12 (SF-12) (Ware et al., 1996), the Health Utilities Index Mark-3 (HUI) (Feeny et al., 1995), and the EUROQOL-5D (Kind, 1996). Each domain consists of two questions that assessed health function in the past 30 days. The actual questions can be found in eTable 1 (Appendix). Each item was scored on a five-point scale ranging from 'none' to 'extreme/cannot do'. For each separate domain, we used factor analysis with polychoric correlations to obtain a factor score which was later converted to scores ranging from 0 to 10 with higher values representing worse health function (Stubbs et al., 2017, 2016c).

\subsection{Statistical analysis}

Data from 69 countries were publicly available. Of these, 10 countries (Austria, Belgium, Denmark, Germany, Greece, Guatemala, Italy, Netherlands, Slovenia, UK) were deleted as sampling information was missing. Furthermore, 10 high-income countries (Finland, France,
Ireland, Israel, Luxembourg, Norway, Portugal, Sweden, Spain, United Arab Emirates) were omitted as the focus of the study was on LMICs. Of the remaining LMICs, Morocco and Latvia were not included as they lacked information on physical activity, and Turkey was also excluded due to lack of several variables pertaining to the analysis. Thus, a total of 46 countries, which were all LMICs according to the World Bank classification in 2003, were included in the analysis (for an overview of the included countries: see e-Table 2). The current analysis was restricted to those who had depression (i.e., depressive episode, brief depressive episode, or subsyndromal depression) $(\mathrm{N}=24,230)$ as the aim of the study was to assess physical activity correlates in this population. A total of 23 potential correlates of physical activity, corresponding to 4 domains (sociodemographics, health behaviour, mental health, physical health) were assessed in patients within the depression spectrum. The selection of these correlates was based on past literature (Davy et al., 2012; Suetani et al., 2016; Vancampfort et al., 2013; Vancampfort et al., 2015c). The differences in the sample characteristics by physical activity levels were tested by Chi-squared tests and Student's $t$-tests for categorical and continuous variables respectively. We conducted multivariable logistic regression with low physical activity as the outcome to assess its correlates by domains (Suetani et al., 2016). Model 1 adjusted for age, sex, and country, while model 2 adjusted for all the variables in the respective domain in addition to age, sex, and country. For all regression analyses, variables were included in the models as categorical variables with the exception of sleep/energy, cognition, pain/discomfort, and mobility (continuous variables). Adjustment for country was done by including dummy variables for each country as in previous World Health Survey publications (Koyanagi and Stickley, 2015; Nuevo et al., 2012). The sample weighting and the complex study design were taken into account in all analyses using the Stata svy command. Results from the logistic regression models are presented as odds ratios (ORs) with $95 \%$ confidence intervals (CIs). The level of statistical significance was set at $\mathrm{P}<0.05$. The statistical analysis was performed with Stata 14.1 (Stata Corp LP, College station, Texas).

\section{Results}

The mean (SD) age of people with depression was 43.1 (16.1) years and $36.1 \%$ were males. $34.8 \%$ engaged in low levels of physical activity. There were no statistically significant differences in the percentage of people not complying with the physical activity recommendations between people with (brief) depressive episode or subsyndromal depression. Sample characteristics are provided in Table 1. Low physical activity was significantly associated with the following characteristics: older age, not married/cohabiting, higher level of wealth, being unemployed, urban setting, inadequate fruit and vegetable consumption, having visual impairment, hearing problem, arthritis, asthma, and diabetes, as well as scoring worse in the domains of sleep/ energy, cognition, pain/discomfort, and mobility. The correlates of low physical activity in the sociodemographic domain estimated by multivariable logistic regression are illustrated in Table 2. In Model 2 (adjusted for all the variables in the respective domain in addition to age, sex, and country), the significant correlates were male sex, older age, not married/cohabiting, being in the richest wealth quintile, unemployment, and urban setting. In terms of factors in the health behaviour domain, in Model 2, inadequate vegetable consumption and frequent heavy drinking (vs. lifetime abstinence) were associated with significantly higher and lower odds for low physical activity respectively. In the mental health domain, only worse sleep/energy was significantly associated with low physical activity. Visual impairment, hearing problems, and mobility difficulty were significant correlates of low physical activity in the physical health domain (Model 2). Although diabetes was a significant correlate in Model 1, it was no longer statistically significant in Model 2. In order to assess whether this was due to the mediating effects of pain/discomfort and/or mobility difficulty associated with diabetes, we excluded these two variables from Model 
Table 1

Sample characteristics (overall and by low physical activity).

\begin{tabular}{|c|c|c|c|c|c|}
\hline \multirow[b]{2}{*}{ Characteristic } & \multirow[b]{2}{*}{ Category } & \multirow[b]{2}{*}{ Total } & \multicolumn{2}{|c|}{$\begin{array}{l}\text { Low physical } \\
\text { activity }\end{array}$} & \multirow[b]{2}{*}{$P$-value ${ }^{a}$} \\
\hline & & & No & Yes & \\
\hline \multicolumn{6}{|c|}{ Sociodemographic domain } \\
\hline Sex & Male & 36.1 & 36.8 & 34.7 & 0.157 \\
\hline \multirow[t]{6}{*}{ Age (years) } & $18-24$ & 15.0 & 16.3 & 12.5 & $<0.001$ \\
\hline & $25-34$ & 21.6 & 25.2 & 14.7 & \\
\hline & $35-44$ & 20.4 & 22.4 & 16.6 & \\
\hline & $45-54$ & 18.0 & 18.1 & 17.7 & \\
\hline & $55-64$ & 11.8 & 9.9 & 15.2 & \\
\hline & $\geq 65$ & 13.3 & 8.0 & 23.3 & \\
\hline Marital status & $\begin{array}{l}\text { Married/ } \\
\text { cohabiting }\end{array}$ & 67.8 & 70.6 & 62.5 & $<0.001$ \\
\hline Education & $\begin{array}{l}\text { Secondary or } \\
\text { higher }\end{array}$ & 33.0 & 33.6 & 31.9 & 0.270 \\
\hline \multirow[t]{5}{*}{ Wealth } & Poorest & 22.3 & 22.7 & 21.4 & 0.010 \\
\hline & Poorer & 21.5 & 22.0 & 20.7 & \\
\hline & Middle & 20.9 & 21.1 & 20.5 & \\
\hline & Richer & 19.5 & 20.0 & 18.8 & \\
\hline & Richest & 15.8 & 14.2 & 18.6 & \\
\hline Unemployed & Yes & 53.5 & 45.8 & 68.2 & $<0.001$ \\
\hline Setting & Urban & 43.5 & 41.1 & 47.9 & 0.001 \\
\hline \multicolumn{6}{|c|}{ Health behaviour domain } \\
\hline Current smoking & Yes & 30.1 & 30.8 & 28.7 & 0.202 \\
\hline Fruit consumption $^{\mathrm{b}}$ & $\begin{array}{l}<5 \text { servings/ } \\
\text { day }\end{array}$ & 94.9 & 93.8 & 96.8 & $<0.001$ \\
\hline $\begin{array}{l}\text { Vegetable } \\
\text { consumption }^{\mathrm{b}}\end{array}$ & $\begin{array}{l}<5 \text { servings/ } \\
\text { day }\end{array}$ & 94.0 & 92.7 & 96.4 & $<0.001$ \\
\hline \multirow[t]{4}{*}{$\begin{array}{l}\text { Alcohol } \\
\text { consumption }\end{array}$} & $\begin{array}{l}\text { Lifetime } \\
\text { abstainer }\end{array}$ & 64.2 & 63.2 & 66.0 & 0.277 \\
\hline & Non-heavy & 31.1 & 32 & 29.4 & \\
\hline & Infrequent heavy & 3.5 & 3.5 & 3.5 & \\
\hline & Frequent heavy & 1.2 & 1.3 & 1.0 & \\
\hline \multicolumn{6}{|c|}{ Mental health domain } \\
\hline \multirow[t]{3}{*}{ Type of depression } & $\begin{array}{l}\text { Sub-syndromal } \\
\text { depression }\end{array}$ & 23.8 & 24.7 & 22.1 & 0.186 \\
\hline & $\begin{array}{l}\text { Brief depressive } \\
\text { episode }\end{array}$ & 20.6 & 20.6 & 20.8 & \\
\hline & $\begin{array}{l}\text { Depressive } \\
\text { episode }\end{array}$ & 55.6 & 54.8 & 57.1 & \\
\hline Anxiety & Yes & 33.1 & 32.1 & 34.9 & 0.088 \\
\hline Sleep/energy ${ }^{c}$ & Mean (SD) & $4.1(2.9)$ & $\begin{array}{l}3.8 \\
(2.8)\end{array}$ & $\begin{array}{l}4.5 \\
(2.9)\end{array}$ & $<0.001$ \\
\hline Cognition $^{c}$ & Mean (SD) & $3.7(2.9)$ & $\begin{array}{l}3.4 \\
(2.8)\end{array}$ & $\begin{array}{l}4.1 \\
(3.0)\end{array}$ & $<0.001$ \\
\hline \multicolumn{6}{|c|}{ Physical health domain } \\
\hline Visual impairment & Yes & 3.7 & 2.1 & 6.5 & $<0.001$ \\
\hline Hearing problem & Yes & 6.1 & 3.2 & 11.4 & $<0.001$ \\
\hline Arthritis & Yes & 23.5 & 22.0 & 26.2 & 0.003 \\
\hline Angina & Yes & 30.6 & 30.2 & 31.4 & 0.393 \\
\hline Asthma & Yes & 10.1 & 9.2 & 11.8 & 0.006 \\
\hline Diabetes & Yes & 5.7 & 4.2 & 8.4 & $<0.001$ \\
\hline Pain/discomfort ${ }^{c}$ & Mean (SD) & $4.7(2.7)$ & $\begin{array}{l}4.3 \\
(2.6)\end{array}$ & $\begin{array}{l}5.1 \\
(2.7)\end{array}$ & $<0.001$ \\
\hline Mobility $^{\mathrm{c}}$ & Mean (SD) & $4.2(3.0)$ & $\begin{array}{l}3.7 \\
(2.8)\end{array}$ & $\begin{array}{l}4.9 \\
(3.2)\end{array}$ & $<0.001$ \\
\hline
\end{tabular}

Abbreviation: SD Standard Deviation

Data are column \% unless otherwise stated.

All estimates are based on weighted sample.

The total amount of moderate to vigorous physical activity over the last week was calculated and those scoring $<150$ min were considered to have low physical activity.

a Differences in sample characteristics by low physical activity was tested by Chisquared tests and Student's $t$-tests for categorical and continuous variables respectively.

b Mexico is not included as data on fruit and vegetable consumption were not collected.

c These variables had scores ranging from 0 to 10 (higher scores indicating worse conditions).

2. The results of this analysis showed that this might have been the case [OR (95\%CI) for diabetes: 1.37 (1.03-1.83); $\mathrm{p}=0.033$ ]. Similarly, we also tested whether the loss of significance of pain (Model 1 vs. Model 2) was due to mediation by mobility difficulties by dropping mobility from Model 2. The OR of pain was statistically significant $[\mathrm{OR}=1.07$;
Table 2

Association between sociodemographic factors and low physical activity estimated by multivariable logistic regression.

\begin{tabular}{|c|c|c|c|c|c|}
\hline Characteristic & Category & $\begin{array}{l}\text { Model } 1 \\
\text { OR }\end{array}$ & $95 \% \mathrm{CI}$ & $\begin{array}{l}\text { Model } 2 \\
\text { OR }\end{array}$ & $95 \% \mathrm{CI}$ \\
\hline \multirow[t]{2}{*}{ Sex } & Female & 1.00 & & 1.00 & \\
\hline & Male & 0.99 & {$[0.86,1.13]$} & $1.33^{* * * x}$ & {$[1.13,1.57]$} \\
\hline \multirow[t]{6}{*}{ Age (years) } & $18-24$ & 1.00 & & 1.00 & \\
\hline & $25-34$ & $0.76^{*}$ & {$[0.60,0.95]$} & 0.89 & {$[0.69,1.15]$} \\
\hline & $35-44$ & 0.91 & {$[0.72,1.14]$} & 1.17 & {$[0.90,1.53]$} \\
\hline & $45-54$ & $1.30 *$ & {$[1.02,1.66]$} & $1.71^{* * * *}$ & {$[1.29,2.26]$} \\
\hline & $55-64$ & $2.06^{t+k * *}$ & {$[1.60,2.66]$} & $2.29^{* * * k}$ & {$[1.70,3.08]$} \\
\hline & $\geq 65$ & $4.52^{* \ldots k * x}$ & {$[3.46,5.90]$} & $4.71^{* * * *}$ & {$[3.51,6.32]$} \\
\hline \multirow[t]{2}{*}{ Marital status } & $\begin{array}{l}\text { Married/ } \\
\text { cohabiting }\end{array}$ & 1.00 & & 1.00 & \\
\hline & Other & $1.21^{*}$ & {$[1.02,1.44]$} & $1.31^{* *}$ & {$[1.11,1.53]$} \\
\hline \multirow[t]{2}{*}{ Education } & $<$ Secondary & 1.00 & & 1.00 & \\
\hline & $\begin{array}{l}\geq \text { Secondary } \\
\text { completed }\end{array}$ & 1.18 & {$[0.98,1.41]$} & 1.12 & {$[0.91,1.38]$} \\
\hline \multirow[t]{5}{*}{ Wealth } & Poorest & 1.00 & & 1.00 & \\
\hline & Poorer & 0.97 & {$[0.81,1.17]$} & 0.98 & {$[0.81,1.19]$} \\
\hline & Middle & 0.99 & {$[0.80,1.23]$} & 0.97 & {$[0.77,1.21]$} \\
\hline & Richer & 0.99 & {$[0.81,1.19]$} & 0.97 & {$[0.80,1.18]$} \\
\hline & Richest & $1.41^{* * k}$ & {$[1.14,1.73]$} & $1.32^{*}$ & {$[1.03,1.68]$} \\
\hline \multirow[t]{2}{*}{ Unemployed } & No & 1.00 & & 1.00 & \\
\hline & Yes & $2.18^{* x+k x}$ & {$[1.84,2.58]$} & $2.26^{* \ldots * *}$ & {$[1.90,2.68]$} \\
\hline \multirow[t]{2}{*}{ Setting } & Rural & 1.00 & & 1.00 & \\
\hline & Urban & $1.32^{* * *}$ & {$[1.12,1.56]$} & $1.24^{*}$ & {$[1.02,1.50]$} \\
\hline
\end{tabular}

Abbreviation: OR Odds Ratio; CI Confidence Interval.

The total amount of moderate to vigorous physical activity over the last week was calculated and those scoring $<150$ min were considered to have low physical activity.

Model 1: Adjusted for sex, age and country. Estimate for age was only adjusted for sex and country, and that of sex was only adjusted for age and country.

Model 2: Adjusted for all covariates in the Table and country.

$* \mathrm{p}<0.05$.

$* * \mathrm{p}<0.01$.

$* * * \mathrm{p}<0.001$

Table 3

Association between health behaviours and low physical activity estimated by multivariable logistic regression.

\begin{tabular}{|c|c|c|c|c|c|}
\hline & & Model 1 & & Model 2 & \\
\hline Characteristic & Category & OR & $95 \% \mathrm{CI}$ & OR & $95 \% \mathrm{CI}$ \\
\hline \multirow[t]{2}{*}{ Current smoking } & No & 1.00 & & 1.00 & \\
\hline & Yes & 0.93 & {$[0.77,1.13]$} & 0.94 & {$[0.75,1.17]$} \\
\hline Fruit & $\geq 5$ & 1.00 & & 1.00 & \\
\hline $\begin{array}{l}\text { consump- } \\
\text { tion }^{\mathrm{a}}\end{array}$ & & & & & \\
\hline (servings/day) & $<5$ & $1.44^{*}$ & {$[1.01,2.05]$} & 1.29 & {$[0.88,1.87]$} \\
\hline $\begin{array}{l}\text { Vegetable } \\
\text { consump- } \\
\text { tion }^{\mathrm{a}}\end{array}$ & $\geq 5$ & 1.00 & & 1.00 & \\
\hline (servings/day) & $<5$ & $1.75^{\star *}$ & {$[1.24,2.47]$} & $1.66^{\text {** }}$ & {$[1.17,2.35]$} \\
\hline \multirow[t]{4}{*}{$\begin{array}{l}\text { Alcohol } \\
\text { consumption }\end{array}$} & $\begin{array}{l}\text { Lifetime } \\
\text { abstainer }\end{array}$ & 1.00 & & 1.00 & \\
\hline & Non-heavy & 0.91 & {$[0.76,1.08]$} & 0.89 & {$[0.71,1.12]$} \\
\hline & $\begin{array}{l}\text { Infrequent } \\
\text { heavy }\end{array}$ & 1.19 & {$[0.85,1.68]$} & 1.02 & {$[0.64,1.64]$} \\
\hline & $\begin{array}{l}\text { Frequent } \\
\text { heavy }\end{array}$ & 0.84 & {$[0.44,1.62]$} & $0.40^{* * *}$ & {$[0.22,0.70]$} \\
\hline
\end{tabular}

Abbreviation: OR Odds Ratio; CI Confidence Interval.

The total amount of moderate to vigorous physical activity over the last week was calculated and those scoring $<150$ min were considered to have low physical activity. Model 1: Adjusted for sex, age and country.

Model 2: Adjusted for all covariates in the Table and country.

${ }^{\mathrm{a}}$ Mexico is not included as data on fruit and vegetable consumption were not collected.

* $\mathrm{p}<0.05$.

$* * \mathrm{p}<0.01$

$95 \% \mathrm{CI}=1.03-1.10 ; \mathrm{p}<0.001]$, suggesting that pain may lead to low physical activity through the mediating effect of mobility difficulty. (Tables. 3-5) 
Table 4

Association between mental health factors and low physical activity estimated by multivariable logistic regression.

\begin{tabular}{|c|c|c|c|c|c|}
\hline Characteristic & Category & $\begin{array}{l}\text { Model } 1 \\
\text { OR }\end{array}$ & $95 \% \mathrm{CI}$ & $\begin{array}{l}\text { Model } 2 \\
\text { OR }\end{array}$ & $95 \% \mathrm{CI}$ \\
\hline \multirow[t]{3}{*}{$\begin{array}{l}\text { Type of } \\
\text { depression }\end{array}$} & $\begin{array}{l}\text { Depressive } \\
\text { episode }\end{array}$ & 1.00 & & 1.00 & \\
\hline & $\begin{array}{l}\text { Sub- } \\
\text { syndromal } \\
\text { depression }\end{array}$ & 1.06 & {$[0.86,1.30]$} & 1.09 & {$[0.87,1.36]$} \\
\hline & $\begin{array}{l}\text { Brief } \\
\text { depressive } \\
\text { episode }\end{array}$ & 0.90 & {$[0.77,1.05]$} & 0.93 & {$[0.79,1.10]$} \\
\hline \multirow[t]{2}{*}{ Anxiety } & No & 1.00 & & 1.00 & \\
\hline & Yes & 1.07 & {$[0.92,1.25]$} & 0.96 & {$[0.82,1.11]$} \\
\hline Sleep/energy ${ }^{a}$ & $\begin{array}{l}\text { per unit } \\
\text { increase }\end{array}$ & $1.05^{* * k}$ & {$[1.02,1.08]$} & $1.04^{\text {*** }}$ & {$[1.01,1.07]$} \\
\hline Cognition $^{\mathrm{a}}$ & $\begin{array}{l}\text { per unit } \\
\text { increase }\end{array}$ & 1.03 & {$[1.00,1.06]$} & 1.02 & {$[0.98,1.05]$} \\
\hline
\end{tabular}

Abbreviation: OR Odds Ratio; CI Confidence Interval.

The total amount of moderate to vigorous physical activity over the last week was calculated and those scoring $<150 \mathrm{~min}$ were considered to have low physical activity.

Model 1: Adjusted for sex, age and country.

Model 2: Adjusted for all covariates in the Table and country.

${ }^{a}$ These variables had scores ranging from 0 to 10 (higher scores indicating worse conditions) and were included in the models as continuous variables.

** $\mathrm{p}<0.01$.

Table 5

Association between physical health factors and low physical activity estimated by multivariable logistic regression.

\begin{tabular}{|c|c|c|c|c|c|}
\hline Characteristic & Category & $\begin{array}{l}\text { Model } 1 \\
\text { OR }\end{array}$ & $95 \% \mathrm{CI}$ & $\begin{array}{l}\text { Model } 2 \\
\text { OR }\end{array}$ & $95 \% \mathrm{CI}$ \\
\hline \multirow[t]{2}{*}{ Visual impairment } & No & 1.00 & & 1.00 & \\
\hline & Yes & $2.06^{\text {*kek }}$ & {$[1.43,2.96]$} & $1.64^{* *}$ & {$[1.14,2.36]$} \\
\hline \multirow{2}{*}{ Hearing problem } & No & 1.00 & & 1.00 & \\
\hline & Yes & $2.20^{\text {stekt }}$ & {$[1.67,2.90]$} & $1.92^{* * * * *}$ & {$[1.45,2.54]$} \\
\hline \multirow[t]{2}{*}{ Arthritis } & No & 1.00 & & 1.00 & \\
\hline & Yes & 1.02 & {$[0.85,1.23]$} & 0.93 & {$[0.77,1.13]$} \\
\hline \multirow[t]{2}{*}{ Angina } & No & 1.00 & & 1.00 & \\
\hline & Yes & 1.01 & {$[0.86,1.19]$} & 0.90 & {$[0.76,1.07]$} \\
\hline \multirow[t]{2}{*}{ Asthma } & No & 1.00 & & 1.00 & \\
\hline & Yes & 1.13 & {$[0.91,1.41]$} & 1.07 & {$[0.84,1.36]$} \\
\hline \multirow[t]{2}{*}{ Diabetes } & No & 1.00 & & 1.00 & \\
\hline & Yes & $1.38^{*}$ & {$[1.05,1.82]$} & 1.23 & {$[0.91,1.65]$} \\
\hline Pain/discomfort ${ }^{\mathrm{a}}$ & $\begin{array}{l}\text { per unit } \\
\text { increase }\end{array}$ & $1.07^{* k * k}$ & {$[1.04,1.10]$} & 1.02 & {$[0.99,1.06]$} \\
\hline Mobility $^{\mathrm{a}}$ & $\begin{array}{l}\text { per unit } \\
\text { increase }\end{array}$ & $1.10^{\text {then }}$ & {$[1.06,1.13]$} & $1.08^{* * * * *}$ & {$[1.05,1.12]$} \\
\hline
\end{tabular}

Abbreviation: OR Odds Ratio; CI Confidence Interval.

The total amount of moderate to vigorous physical activity over the last week was calculated and those scoring $<150$ min were considered to have low physical activity. Model 1: Adjusted for sex, age and country.

Model 2: Adjusted for all covariates in the Table and country.

a These variables had scores ranging from 0 to 10 (higher scores indicating worse conditions) and were included in the models as continuous variables.

$* * \mathrm{p}<0.01$.

$* * * \mathrm{p}<0.001$

\section{Discussion}

\subsection{General findings}

To the best of our knowledge this is the first multi-national study exploring physical activity correlates in community-dwelling people with depression. The current data are among the first to report on physical activity correlates in people with depression in LMICs. Our findings support the hypothesis that, in people with depression in LMICs, physical activity participation is a complex behaviour that is influenced by many different factors. In summary, our data suggest that in particular male sex, older age, not being married/cohabiting, being wealthy, unemployment, living in an urban setting, lower vegetable consumption, worse sleep/energy and the presence of somatic comorbidity are all associated with lower physical activity levels among those with depression. Depression type was not significantly associated with physical activity levels. A clinical implication of our findings is that to achieve substantial physical activity behaviour change in people suffering from depressive symptoms, physical activity interventions should ideally target changes in different domains and should be tailored based on the individual's needs and barriers.

Knowledge about correlates of physical activity behaviour helps to identify high-risk persons with depressive symptoms in whom physical activity is less likely, and who may therefore require more intensive and targeted interventions. Consistent with data from Western countries (Vancampfort et al., 2015c) we found that older age and the presence of somatic co-morbidities were associated with lower physical activity and these are likely to become a major public health issues in LMICs as the number of old people is currently rising (Beard et al., 2012). Our data also confirm previous findings (Stubbs et al., 2016b) that mobility limitations and pain, which are more prevalent in older patients and in those with somatic co-morbidities, are associated with lower physical activity levels. It is known that people with depression may be more likely to have chronic pain (Stubbs et al., 2016d; Thompson et al., 2016), which impacts upon mobility (Stubbs et al., 2016e) and is associated with being less physically active (Stubbs et al., 2014).

Our data indicate that health care professionals and policy makers should also consider the socioeconomic status of people with depression. For example, not being married/cohabiting was associated with lower physical activity levels. It might be hypothesized that those who are not married or cohabiting feel lonelier. Loneliness has been associated with lower physical activity in the general population (Hawkley et al., 2009) and in people with psychosis (Suetani et al., 2016). Furthermore, we found that participants who were employed were more physically active. Next to physically demanding labour, active transport to and from work might be an underlying reason. Speculatively, employment may offer opportunities for people with depression to connect socially, enhance social functioning and consequently have more opportunity to be physically active (Böhm et al., 2016; Sarkar et al., 2016; Suetani et al., 2016). Future research should explore whether social support might assist people with depression in LMICs to become more physically active. However, this family support may not be possible, unless stigma associated with mental illness in LMICs is tackled. In addition, the amount and type of social support necessary to begin or maintain physical activity behaviour should be investigated. In contrast to the "Western" literature where differences in levels of physical activity between men and women with depression tend to be smaller with conflicting results, our data in LMICs clearly demonstrate that men with depression are significantly less physically active. It is established that women, in particular from rural settings in LMICs, are at the centre of the economic production for the family (Pathai et al., 2013). Also contrary to Western societies (Vancampfort et al., 2012b), increased wealth was associated with lower levels of physical activity. Economic transition to a higher income economy is usually associated with a move from a predominantly agrarian and/or subsistence economy to a predominantly industrial and/or service-based economy resulting in changes in occupational patterns, leisure time activities and diet. For example, it might be that a more Western lifestyle, mainly observed in urban centres of LMICs and including the use of motorized transport, less labour-demanding jobs, and physically undemanding, mostly screen-based leisure, is responsible for lower levels of physical activity in those who can afford such a lifestyle. Next to this, the urban food environment is characterized by a high availability of calorie-dense, cheap foods and lower consumption of fruit and vegetables (Solomons and Gross, 1995), which might explain why physical inactivity is associated with lower vegetable consumption. Differences between rural and urban settings might also be related to the fact that an urban 
environment in most LMICs is not conducive to safe physical activity due to unsafe traffic, increased risk of crime and fear of crime (De Bourdeaudhuij et al., 2015), which are in turn linked to stress and depression (Smit et al., 2016).

Finally, a rather counterintuitive finding was the association between higher physical activity levels and regular heavy drinking. Research from Western countries suggest that until a certain level of alcohol consumption or until a 'ceiling effect' is reached, higher consumption of alcohol is associated with higher levels of physical activity (French et al., 2009; Vancampfort et al., 2015a). It might be that individuals who frequently drink have an increased affinity for physical activity, perhaps because of its reward-related reinforcing effects (Leasure et al., 2014). Alternatively, some forms of physical activity (e.g., team sports participation) may be linked to post-game alcohol consumption. However, more research is needed to understand this relationship.

\subsection{Policy-related and clinical implications}

First, although economic growth and urbanization offer many opportunities in LMICs, including potential access to better mental and physical health care, today's urban environments and a more Western lifestyle can concentrate health risks and introduce new hazards, such as a higher risk for non-communicable diseases. A stronger emphasis on physical activity interventions focusing on barriers for people with mental illness is needed. Such interventions must be linked to national policies in order to accelerate the implementation of effective and promising strategies on a large scale. Our data confirm a recent call (Sallis et al., 2016a) for a clear evidence base of and consensus on effective physical activity interventions that will support national health policy making in LMICs. For example, our data show that physical activity supportive environments should become a vital component of a mental and physical health policy in LMICs. There is a high need to improve the availability and quality of sidewalks, pedestrian zones, bicycle facilities, and factors affecting intersection quality (e.g., crosswalks, pedestrian signals) in urban centres. Improved design of physical activity stimulating urban environments has the potential to contribute nearly $90 \mathrm{~min} /$ week of physical activity, which is $60 \%$ of the $150 \mathrm{~min} /$ week recommended in physical activity guidelines (Sallis et al., 2016b).

Next to this a curriculum review for clinical and public health courses should be undertaken as well to include psychical activity in the management of mental disorders such as depression. Well-tailored continuous medical education should be conducted in medical settings in LMICs, and can be used to equip medical professionals with the necessary knowledge to promote physical activity in people with depression

Third, the current findings provide important clinical implications regarding the design and delivery of physical activity interventions targeting people with depression in LMICs. Results suggest a need to tailor different types of physical activity interventions to different age groups and to consider somatic co-morbidities, pain/discomfort and mobility problems. We suggest future research explore a dual strategy of physical activity promotion in low resource settings involving a smaller number of trainers/supervisors (e.g., exercise physiologists and physiotherapists) and a larger cohort of face-to-face clinical practitioners (e.g., nurses). This method has been successfully employed for cognitive behavioural therapy in trials in LMICs (Naeem et al., 2015, 2014). A stepped-care approach, where people with depression start with self-management strategies to increase their physical activity levels may be a feasible strategy in low resource settings. Then, if patients still do not achieve physical activity recommendations, they could continue with a manualized approach under the supervision of a nonspecialist clinician (e.g., nurses, occupational therapists). Patients would only be referred to a specialist supervisor (e.g., exercise physiologists and physiotherapists) if no significant increase in physical activity occurred, for example due to somatic co-morbidities, pain, sleep problems or mobility problems or for specific populations such as the elderly. It is known that inclusion of exercise physiologists or physiotherapists reduces drop-out rates from physical activity interventions and consequently improves outcomes in people with depression (Stubbs et al., 2016f). Careful consideration of what physical activity implementation strategies would be most efficacious, and evaluation of this stepped-care approach, is essential.

\subsection{Limitations}

The current data should be considered in the light of some limitations. First, the study is cross-sectional, therefore cause and effect cannot be deduced. Therefore, future prospective research is required to disentangle the directionality of the relationships observed. Second, due to the 12-month timeframe for a depression diagnosis, participants without current depressive symptoms might have been included. Thus, some level of misclassification may have affected the results. Third, physical activity was measured with a self-report questionnaire, which is known to be less accurate than objective assessments (Soundy et al., 2014; Stubbs et al., 2016a). For example, it is well recognized that selfreported measures, especially the IPAQ, can overestimate physical activity levels (Ainsworth et al., 2006). Fourth, the current study only included non-institutionalized people and therefore, the current data are not generalizable to non-community settings. Fifth, we considered the physical activity correlates in people with depression in LMICs as a whole and did not make any further distinction in geographical or cultural regions. There are vast differences across the 46 countries in terms of health care and political systems, literacy, culture and religion that might impact on both health behaviour and attitudes/knowledge regarding physical activity, differences which were not accounted for in our analyses. Finally, future studies would benefit from assessing to what extent other sociodemographic factors such as family composition (e.g. having children or not) and ethnicity as well as other macro-level environmental factors such as food insecurity, civil conflicts, and extreme weather in LMICs are linked to physical inactivity in this population.

In conclusion, our data have considered in detail the correlates of recommended physical activity levels among people with depression in a large cohort of 24,230 people from 46 LMICs. These findings provide guidance for future population level interventions across LMICs to help people with depression to become more active.

\section{Declaration of interest}

The authors declare that there are no conflicts of interest to report.

\section{Contributors}

Access to the World Health Survey data collection was obtained by Dr. Brendon Stubbs. Analyses were performed by Dr. Ai Koyanagi and Dr. Brendon Stubbs. Dr. Davy Vancampfort wrote a first draft which was reviewed and revised in several rounds by the other co-authors. All authors approved the final version and all authors certify that they have participated sufficiently in the work to believe in its overall validity and to take public responsibility for appropriate portions of its content.

The authors declare that there are no conflicts of interest to report.

\section{Role of funding source}

Ai Koyanagi's work is supported by the Miguel Servet contract financed by the CP13/00150 and PI15/00862 projects, integrated into the National R $+\mathrm{D}+\mathrm{I}$ and funded by the ISCIII - General Branch Evaluation and Promotion of Health Research - and the European Regional Development Fund (ERDF-FEDER). We certify that no party having a direct interest in the results of the research supporting this article has or will confer a benefit on us or on any organization with which we are associated. 


\section{Acknowledgements}

None.

\section{Appendix A. Supplementary material}

Supplementary data associated with this article can be found in the online version at http://dx.doi.org/10.1016/j.jad.2017.06.012.

\section{References}

Ainsworth, B.E., Macera, C.A., Jones, D.A., Reis, J.P., Addy, C.L., Bowles, H.R., Kohl 3rd, H., 2006. Comparison of the 2001 BRFSS and the IPAQ physical activity questionnaires. Med. Sci. Sports Exerc. 38, 1584-1592.

Atkinson, K., Lowe, S., Moore, S., 2016. Human development, occupational structure and physical inactivity among 47 low and middle income countries. Prev. Med. Rep. 3, $40-45$.

Ayuso-Mateos, J.L., Nuevo, R., Verdes, E., Naidoo, N., Chatterji, S., 2010. From depressive symptoms to depressive disorders: the relevance of thresholds. Br. J. Psychiatry 196, 365-371.

Beard, J., Biggs, S., Bloom, D., Fried, L., Hogan, P., Kalache, R., Olshansky, J., 2012. Global Population Ageing: Peril or Promise? World Economic Forum, Geneva.

Bishwajit, G., O'Leary, D.P., Ghosh, S., Sanni, Y., Shangfeng, T., Zhanchun, F., 2017. Association between depression and fruit and vegetable consumption among adults in South Asia. BMC Psychiatry 17, 15.

Böhm, A.W., Mielke, G.I., da Cruz, M.F., Ramires, V.V., Wehrmeister, F.C., 2016. Social support and leisure-time physical activity among the elderly: a population-based study. J. Phys. Act. Health 13, 599-605.

Correll, C.U., Solmi, M., Veronese, N., Bortolato, B., Rosson, S., Santonastaso, P., Thapa, N., Fornaro, M., Gallicchio, D., Collantoni, E., Pigato, G., Favaro, A., Monaco, F., Kohler, C., Vancampfort, D., Ward, P.B., Gaughran, F., Carvalho, A.F., Stubbs, B. 2017. Prevalence, incidence and mortality from cardiovascular disease in patients with pooled and specific severe mental illness: a large-scale meta-analysis of 3,211,768 patients and 113,383,368 controls. World Psychiatry 16 (2), 163-180.

Craig, C., Marshall, A., Sjostrom, M., Bauman, A., Booth, M., Ainsworth, B., Pratt, M., Ekelund, U., Yngve, A., Sallis, J., Oja, P., 2003. International physical activity questionnaire: 12-country reliability and validity. Med. Sci. Sports Exerc. 35, 1381-1395.

De Bourdeaudhuij, I., Van Dyck, D., Salvo, D., Davey, R., Reis, R.S., Schofield, G., Sarmiento, O.L., Mitas, J., Christiansen, L.B., MacFarlane, D., 2015. International study of perceived neighbourhood environmental attributes and Body Mass Index: ipen Adult study in 12 countries. Int. J. Behav. Nutr. Phys. Act. 12, 62.

Djernes, J.K., 2006. Prevalence and predictors of depression in populations of elderly: a review. Acta Psychiatr. Scand. 113, 372-387.

Feeny, D., Furlong, W., Boyle, M., Torrance, G.W., 1995. Multi-attribute health status classification systems. Health utilities index. PharmacoEconomics 7, 490-502.

Freeman, E.E., Roy-Gagnon, M.H., Samson, E., Haddad, S., Aubin, M.J., Vela, C., Zunzunegui, M.V., 2013. The global burden of visual difficulty in low, middle, and high income countries. PLoS One 8, e63315.

French, M.T., Popovici, I., Maclean, J.C., 2009. Do alcohol consumers exercise more? Findings from a national survey. Am. J. Health Promot. 24, 2-10.

Hawkley, L.C., Thisted, R.A., Cacioppo, J.T., 2009. Loneliness predicts reduced physical activity: cross-sectional \& longitudinal analyses. Health Psychol. 28, 354.

Kessler, R.C., Ustun, T.B., 2004. The World Mental Health (WMH) Survey Initiative Version of the World Health Organization (WHO) Composite International Diagnostic Interview (CIDI). Int J Methods Psychiatry Research 13, 93-121.

Kessler, R.C., Berglund, P., Demler, O., et al., 2003. The epidemiology of major depressive disorder: results from the national comorbidity survey replication (ncs-r). JAMA 289, 3095-3105.

Kind, P., 1996. The Euroqol instrument: an index of health-related quality of life. In: Spiker, B. (Ed.), Quality of Life and Pharmacoeconomics in Clinical Trial. LippincottRaven Publishers, pp. 191-201.

Koyanagi, A., Stickley, A., 2015. The association between sleep problems and psychotic symptoms in the general population: a global perspective. Sleep 38, 1875-1885.

Leasure, J.L., Neighbors, C., Henderson, C.E., Young, C.M., 2014. Exercise and alcohol consumption: What we know, what we need to know, and why it is important. Front. Psychiatry 6 (156-156).

Mammen, G., Faulkner, G., 2013. Physical activity and the prevention of depression: a systematic review of prospective studies. Am. J. Prev. Med. 45, 649-657.

Moussavi, S., Chatterji, S., Verdes, E., Tandon, A., Patel, V., Ustun, B., 2007. Depression, chronic diseases, and decrements in health: results from the World Health Surveys. Lancet 370, 851-858.

Naci, H., Ioannidis, J.P.A., 2013. Comparative effectiveness of exercise and drug interventions on mortality outcomes: metaepidemiological study. BMJ (Clinical Res. Ed.), 347, p. 5577.

Naeem, F., Sarhandi, I., Gul, M., Khalid, M., Aslam, M., Anbrin, A., Saeed, S., Noor, M., Fatima, G., Minhas, F., 2014. A multicentre randomised controlled trial of a carer supervised culturally adapted CBT (CaCBT) based self-help for depression in Pakistan. J. Affect. Disord. 156, 224-227.

Naeem, F., Saeed, S., Irfan, M., Kiran, T., Mehmood, N., Gul, M., Munshi, T., Ahmad, S., Kazmi, A., Husain, N., 2015. Brief culturally adapted CBT for psychosis (CaCBTp): a randomized controlled trial from a low income country. Schizophr. Res. 164,
$143-148$.

Nuevo, R., Chatterji, S., Verdes, E., Naidoo, N., Arango, C., Ayuso-Mateos, J.L., 2012. The continuum of psychotic symptoms in the general population: a cross-national study. Schizophr. Bull. 38, 475-485.

Patel, V., Araya, R., Chatterjee, S., Chisholm, D., Cohen, A., De Silva, M., Hosman, C., McGuire, H., Rojas, G., van Ommeren, M., 2007. Treatment and prevention of mental disorders in low-income and middle-income countries. Lancet 370, 991-1005.

Pathai, S., Gilbert, C., Weiss, H.A., Cook, C., Wood, R., Bekker, L.-G., Lawn, S.D., 2013. Frailty in HIV-infected adults in South Africa. J. Acquir. Immune Defic. Syndr. (1999) $62,43$.

Pengpid, S., Peltzer, K., Kassean, H.K., Tsala, J.P.T., Sychareun, V., MüllerRiemenschneider, F., 2015. Physical inactivity and associated factors among university students in 23 low-, middle-and high-income countries. Int. J. Public Health 60, 539-549.

Rose, G.A., 1962. The diagnosis of ischaemic heart pain and intermittent claudication in field surveys. Bull. World Health Organ. 27, 645-658.

Sallis, J.F., Bull, F., Guthold, R., Heath, G.W., Inoue, S., Kelly, P., Oyeyemi, A.L., Perez, L.G., Richards, J., Hallal, P.C., 2016a. Progress in physical activity over the Olympic quadrennium. Lancet 388, 1325-1336.

Sallis, J.F., Cerin, E., Conway, T.L., Adams, M.A., Frank, L.D., Pratt, M., Salvo, D., Schipperijn, J., Smith, G., Cain, K.L., 2016b. Physical activity in relation to urban environments in 14 cities worldwide: a cross-sectional study. Lancet 387, 2207-2217.

Sarkar, S., Taylor, W.C., Lai, D., Shegog, R., Paxton, R.J., 2016. Social support for physical activity: comparison of family, friends, and coworkers. Work 55, 893-899.

Schuch, F., Vancampfort, D., Firth, J., Rosenbaum, S., Ward, P., Reichert, T., Bagatini, N.C., Bgeginski, R., Stubbs, B., 2017. Physical activity and sedentary behavior in people with major depressive disorder: a systematic review and meta-analysis. J. Affect. Disord. 210, 139-150.

Schuch, F.B., Vancampfort, D., Richards, J., Rosenbaum, S., Ward, P.B., Stubbs, B., 2016 a. Exercise as a treatment for depression: a meta-analysis adjusting for publication bias. J. Psychiatr. Res. 77, 42-51.

Schuch, F.B., Vancampfort, D., Sui, X., Rosenbaum, S., Firth, J., Richards, J., Ward, P.B., Stubbs, B., 2016b. Are lower levels of cardiorespiratory fitness associated with incident depression? A systematic review of prospective cohort studies. Prev. Med. 93, $159-165$.

Seldenrijk, A., Vogelzangs, N., Batelaan, N.M., Wieman, I., van Schaik, D.J., Penninx, B.J., 2015. Depression, anxiety and 6-year risk of cardiovascular disease. J. Psychosom. Res. 78, 123-129.

Smit, W., De Lannoy, A., Dover, R.V., Lambert, E.V., Levitt, N., Watson, V., 2016. Making unhealthy places: the built environment and non-communicable diseases in Khayelitsha, Cape Town. Health Place 39, 196-203.

Solomons, N.W., Gross, R., 1995. Urban nutrition in developing countries. Nutr. Rev. 53, 90-95.

Soundy, A., Roskell, C., Stubbs, B., Vancampfort, D., 2014. Selection, use and psychometric properties of physical activity measures to assess individuals with severe mental illness: a narrative synthesis. Arch. Psychiatr. Nurs. 28, 135-151.

Stubbs, B., Patchay, S., Soundy, A., Schofield, P., 2014. The avoidance of activities due to fear of falling contributes to sedentary Behavior among community-dwelling older adults with chronic musculoskeletal pain: a multisite observational study. Pain. Med. 15 (11), 1861-1871.

Stubbs, B., Firth, J., Berry, A., Schuch, F.B., Rosenbaum, S., Gaughran, F., Veronesse, N., Williams, J., Craig, T., Yung, A.R., Vancampfort, D., 2016a. How much physical activity do people with schizophrenia engage in? A systematic review, comparative meta-analysis and meta-regression. Schizophr. Res. 176 (2-3), 431-440.

Stubbs, B., Koyanagi, A., Schuch, F., Firth, J., Rosenbaum, S., Gaughran, F., Mugisha, J., Vancampfort, D., 2016b. Physical activity levels and psychosis: a mediation analysis of factors influencing physical activity target achievement among 204186 people across 46 low- and middle-income countries. Schizophr. Bull. 43 (3), 536-545.

Stubbs, B., Koyanagi, A., Schuch, F., Firth, J., Rosenbaum, S., Veronese, N., Solmi, M., Mugisha, J., Vancampfort, D., 2016c. Physical activity and depression: a large cross-sectional, population-based study across 36 low-and middle-income countries. Acta Psychiatr. Scand. 134, 546-556.

Stubbs, B., Koyanagi, A., Thompson, T., Veronese, N., Carvalho, A.F., Solomi, M., Mugisha, J., Schofield, P., Cosco, T., Wilson, N., 2016d. The epidemiology of back pain and its relationship with depression, psychosis, anxiety, sleep disturbances, and stress sensitivity: data from 43 low-and middle-income countries. General. Hosp. Psychiatry 43, 63-70.

Stubbs, B., Schofield, P., Patchay, S., 2016e. Mobility limitations and fall-related factors contribute to the reduced health-related quality of life in older adults with chronic musculoskeletal pain. Pain Pract. 16, 80-89.

Stubbs, B., Vancampfort, D., Rosenbaum, S., Ward, P.B., Richards, J., Soundy, A. Veronese, N., Solmi, M., Schuch, F.B., 2016f. Dropout from exercise randomized controlled trials among people with depression: a meta-analysis and meta regression. J. Affect. Disord. 190, 457-466.

Stubbs, B., Koyanagi, A., Schuch, F., Firth, J., Rosenbaum, S., Gaughran, F., Mugisha, J., Vancampfort, D., 2017. Physical activity levels and psychosis: a mediation analysis of factors influencing physical activity target achievement among 204186 people across 46 low-and middle-income countries. Schizophr. Bull. 43, 536-545.

Suetani, S., Waterreus, A., Morgan, V., Foley, D.L., Galletly, C., Badcock, J.C., Watts, G., McKinnon, A., Castle, D., Saha, S., Scott, J.G., McGrath, J.J., 2016. Correlates of physical activity in people living with psychotic illness. Acta Psychiatr. Scand. 134, 129-137.

Thompson, T., Correll, C.U., Gallop, K., Vancampfort, D., Stubbs, B., 2016. Is pain perception altered in people with depression? A systematic review and meta-analysis of experimental pain research. J. Pain 17, 1257-1272.

Vancampfort, D., Hert, M.D., Skjerven, L.H., Gyllensten, A.L., Parker, A., Mulders, N., 
Nyboe, L., Spencer, F., Probst, M., 2012a. International Organization of Physical Therapy in Mental Health consensus on physical activity within multidisciplinary rehabilitation programmes for minimising cardio-metabolic risk in patients with schizophrenia. Disabil. Rehabil. 34, 1-12.

Vancampfort, D., Knapen, J., Probst, M., Scheewe, T., Remans, S., De Hert, M., 2012b. A systematic review of correlates of physical activity in patients with schizophrenia. Acta Psychiatr. Scand. 125, 352-362.

Vancampfort, D., Correll, C.U., Probst, M., Sienaert, P., Wyckaert, S., De Herdt, A., Knapen, J., De Wachter, D., De Hert, M., 2013. A review of physical activity correlates in patients with bipolar disorder. J. Affect. Disord. 145, 285-291.

Vancampfort, D., De Hert, M., Stubbs, B., Soundy, A., De Herdt, A., Detraux, J., Probst, M., 2015a. A systematic review of physical activity correlates in alcohol use disorders. Arch. Psychiatr. Nurs. 29, 196-201.

Vancampfort, D., Mitchell, A.J., De Hert, M., Sienaert, P., Probst, M., Buys, R., Stubbs, B., 2015b. Type 2 diabetes in patients with major depressive disorder: a meta-analysis of prevalence estimates and predictors. Depress. Anxiety 32 (10), 763-773.

Vancampfort, D., Stubbs, B., Sienaert, P., Wyckaert, S., De Hert, M., Rosenbaum, S. Probst, M., 2015c. What are the factors that influence physical activity participation in individuals with depression? A review of physical activity correlates from 59 studies. Psychiatr. Danub. 27, 210.

Vancampfort, D., Correll, C.U., Galling, B., Probst, M., De Hert, M., Ward, P.B.,
Rosenbaum, S., Gaughran, F., Lally, J., Stubbs, B., 2016. Diabetes mellitus in people with schizophrenia, bipolar disorder and major depressive disorder: a systematic review and large scale meta-analysis. World Psychiatry 15 (2), 166-174.

Vos, T., Allen, C., Arora, M., Barber, R.M., Bhutta, Z.A., Brown, A., Carter, A., Casey, D.C., Charlson, F.J., Chen, A.Z., 2016. Global, regional, and national incidence, prevalence, and years lived with disability for 310 diseases and injuries, 1990-2015: a systematic analysis for the Global burden of disease study 2015. Lancet 388, 1545-1602.

Walker, E.R., McGee, R.E., Druss, B.G., 2015. Mortality in mental Ddsorders and global disease burden implications: a systematic review and meta-analysis. JAMA Psychiatry 72 (4), 334-341.

Ware Jr., J., Kosinski, M., Keller, S.D., 1996. A 12-Item Short-Form Health Survey: construction of scales and preliminary tests of reliability and validity. Med. Care 34, $220-233$.

Wong, K.O., Hunter Rowe, B., Douwes, J., Senthilselvan, A., 2013. Asthma and wheezing are associated with depression and anxiety in adults: an analysis from 54 countries. Pulm. Med. 2013, 929028.

World Health Organization, 1993. The ICD-10 classification of mental and behavioural disorders: diagnostic criteria for research, World Health Organization, Geneva.

World Health Organization, 2002. International guide for monitoring alcohol consumption and related harm, World Health Organization, Geneva. 